\title{
Psychotherapy change process research: Realizing the promise
}

\author{
ROBERT ELLIOTT \\ Counselling Unit, University of Strathclyde, Glasgow, UK \\ (Received 3 fuly 2009; revised 24 October 2009; accepted 3 November 2009)
}

\begin{abstract}
Change process research (CPR) is the study of the processes by which change occurs in psychotherapy and is a necessary complement to randomized clinical trials and other forms of efficacy research. In this article the author describes and evaluates four types of CPR. The first three are basic designs and include quantitative process-outcome, qualitative helpful factors, and microanalytic sequential process; the fourth, the significant events approach, refers to methods such as task analysis and comprehensive process analysis that integrate the first three. The strengths and weaknesses of each design are described and summarized using both causal and practical criteria as part of an overall argument for systematic methodological pluralism.
\end{abstract}

Keywords: process research; outcome research; philosophical/theoretical issues in therapy research; research methodology

The term change process research (CPR) was introduced more than 20 years ago to refer to research that overcomes the old process-outcome dichotomy by focusing "on identifying, describing, explaining, and predicting the effects of the processes that bring about therapeutic change" (Greenberg, 1986, p. 4). Greenberg described two kinds of CPR: (a) task analysis of significant therapy events and (b) microanalytic research of sequences of client and therapist in-session behaviors. In the intervening years, the term has come to refer more broadly to the study of the processes by which change occurs in psychotherapy, including both the in-therapy processes that bring about change and the unfolding sequence of client change (which changes occur first and lead to what subsequence client changes). As a result, it has subsequently become clear that there are more than two genres of CPR, based on the different types of evidence that can be used to infer the causal operation of a particular therapeutic process.

$\mathrm{CPR}$ is a necessary complement to randomized clinical trials (RCTs) and experimental or interpretive single-case causal designs. Both types of causal research design focus narrowly on establishing the existence of a causal relationship between therapy and client change but do not specify the nature of that relationship. Furthermore, it is now understood that scientists commonly do not accept newly proposed causal relationships unless there is a plausible explanation or narrative linking cause to effect, as Haynes and O'Brien (2000) indicate in framing the following four requirements for valid causal inference:

1. The two variables must covary.

2. The hypothesized causal variable must reliably precede the effect variable.

3. Realistic alternative explanations for the observed covariance must be reasonably excluded.

4. There must be a plausible explanation ("logical mechanism") for the hypothesized causal relation.

For example, many researchers (e.g., Herbert et al., 2000) initially rejected the causal efficacy of eye movement desensitization and reprocessing (EMDR; Shapiro, 1995), even in the face of RCT evidence supporting the first three conditions listed, because they felt that there was not a convincing causal explanation of the process by which eye movements might lead to resolution of posttrauma difficulties in clients. Subsequent research (Christman, Garvey, Propper, \& Phaneuf, 2003) has significantly contributed to the credibility of EMDR by providing evidence for a biological basis for its effectiveness. 
In fact, CPR offers several strategies for uncovering and evaluating explanations for client change. These include three basic genres of CPR, ranging from the venerable process-outcome paradigm of using in-therapy process variables to predict outcome, to the more recent approach of asking clients to describe the aspects of therapy that helped them change (referred to here as the helpful factors design), to the microanalysis of sequential dependencies among successive client and therapist responses (the sequential process design). In addition, a more complex research paradigm, referred to here as the significant events approach, has also emerged, combining multiple elements of the more basic approaches to provide more comprehensive strategies for understanding how change occurs in therapy.

Although CPR is of fundamental importance for advancing the science of psychotherapy, some approaches (e.g., sequential process) have been neglected, whereas some might regard others as overused (i.e., process-outcome design). Most researchers seem to restrict themselves to a single genre to the exclusion of the others and have rarely used more than one genre in a given study. The principle of multiple operations (e.g., Cook \& Campbell, 1979), however, suggests that it is important to have a range of methods to apply to a particular measurement situation, here the measurement of change processes in psychotherapy, because each method has different particular strengths and weaknesses.

In this report, I provide an overview of four major approaches to identifying and evaluating psychotherapy change processes. This is a personal view of CPR research, informed by my experiences as a psychotherapy researcher over the past 35 years. For each of these four key types of CPR, I first describe its major features, uses, and strengths. Then I outline its main drawbacks or vulnerabilities and conclude with recommendations and thoughts about ways to make more effective use of each particular approach.

\section{The Quantitative Process-Outcome Design}

The most obvious way to do empirical research on connections between in-session processes and posttherapy outcome is to sample key processes from one or more therapy sessions and to use these to predict posttherapy outcome. This is the most popular form of CPR and one of the most common types of therapy research in general. According to Orlinsky, Rønnestad, and Willutzki (2004), several thousand separate process-outcome research findings are available in the literature, with process and outcome being measured on various dimensions and from client, therapist, and observer perspectives. This is such a logical, intuitively obvious approach that researchers seem to find themselves compelled to apply it again and again. Relational variables such as therapeutic alliance have been studied the most (e.g., Martin, Garske, \& Davis, 2000), but technique variables like transference interpretation have also come in for extensive research, although with somewhat mixed results (cf. Orlinsky et al., 2004). Most often, natural variations in the predictor variable can be observed (e.g., more vs. fewer relational interpretations; e.g., Crits-Christoph \& Connolly Gibbons, 2002); or it can be experimentally manipulated, for example, by asking therapists to increase the number of self-disclosures offered (Barrett \& Berman, 2001).

\section{Strengths}

In my view, the main advantages of the processoutcome paradigm for CPR are that it is intuitively appealing and widely used and accepted. This means that if you do a process-outcome study, you will have a lot of company, and people will easily understand what you did. Indeed, even critics such as Stiles (1996) concede that process-outcome research makes sense for measures of good process, such as therapeutic alliance or depth of client exploration, where there is no such thing as too much of a good thing. For others, such as Kazdin (2009), sophisticated quantitative process-outcome research of causal mediators and mechanisms in therapy is the essential next step in the development of psychotherapy research.

\section{Limitations}

A wide variety of problems with the process-outcome design have by now been documented, indicating that making a monoculture of the approach is unwise. In general, these limitations involve various forms of attenuation stemming from the distance between the process measured and the outcome of therapy, that is to say, from the method's indirectness: The change process is treated as a black box where only input and output are looked at, thus ignoring everything in the middle, what Cook and Campbell (1979) referred to as the "causal micro-mediating process." Difficulties of causal attenuation seem to fall largely into two groups: (a) measurement problems such as attenuation resulting from unreliability, basement and ceiling effects, undersampling of therapy process, and sampling the wrong area of the dose-response curve; and (b) internal validity problems with reverse and third-variable causation in the correlational designs typically used in process-outcome research. For 
example, internal validity issues have led advocates of RCTs to refuse to accept process-outcome evidence in reviews aimed at formulating evidence-based practice (e.g., DeRubeis, Brotman, \& Gibbons, 2005;

AQ1 National Collaborating Centre for Mental Health, 2009).

Most strikingly, Stiles and colleagues (Stiles, 1988; Stiles \& Shapiro, 1989, 1994) have put forward a devastating third-variable critique of the process-outcome paradigm, which they argue portrays psychotherapy as a "ballistic" (i.e., predetermined) rather than a responsive activity. Their key argument goes as follows:

1. Clients with fewer internal resources (e.g., less self-insight) are likely to have poorer outcomes than clients with more internal resources.

2. When confronted with clients with fewer resources, skilled therapists will be responsive and will thus routinely offer more of the putative active ingredient to the clients (e.g., interpretation).

3. If therapists are perfectly and successfully responsive, all clients will have the same outcome, and the correlation between the theorized effective ingredient and outcome will be zero.

4. If therapists are only partially successful in their responsiveness, they will be unable to totally ameliorate their clients' initial limitations, and clients offered more of the effective ingredient will actually have poorer outcomes; that is, there will be a negative correlation.

In fact, Stiles's responsiveness theory is quite consistent with the generally disappointing results of process-outcome research, at least as it has been applied to therapist technique variables such as relational interpretations (Orlinsky et al., 2004).

However, even setting the responsiveness critique aside, there are additional problems with the processoutcome research program. Take, for example, therapist empathy, which is one of the strongest, most consistent predictors of therapy outcome: In a meta-analysis of process-outcome research on therapist empathy, my colleagues and I (Bohart, Elliott, Greenberg, \& Watson, 2002) reported a mean weighted effect size (Pearson $r$ ) of .32. Although substantial by the standards of social science research, this accounts for a relatively small proportion of the variance in client outcome, a very disappointing showing when compared with Rogers's (1957) hypothesis that the relational conditions were "necessary and sufficient" for client change (i.e., would correlate perfectly with client outcome).

In fact, given the complexities of the therapy situation and the difficulties of therapy research,
.32 is possibly about as large as it is possible to obtain. Following DeRubeis (2007), several arguments can be made. First, there are very large differences among clients (e.g., pretherapy problem severity and complexity; disordered personality processes) that strongly affect outcome. For example, a substantial proportion of clients have enough resilience that they are capable of deriving benefit from even a moderately unempathic therapist. Also, another, probably smaller subset of clients are psychologically fragile or in such hostile life circumstances that even with the most empathic therapist they cannot be expected to show much in the way of benefit over the course of the brief therapies studied in this body of research.

Second, in general, the therapist predictor variable (e.g., empathy) is likely to suffer from restricted range; that is, most or all of the therapists studied will be at least moderately empathic as a result of native skill, selection, training, or supervision. To test Rogers's prediction fully, one would need therapists evenly distributed across the full range of competence! In fact, it would be unethical to design such a study because it would require either deliberately selecting incompetent therapists or training them to treat their clients in ways that violate core professional ethical values such as respect and beneficence.

Third, one would have to measure empathy and outcome perfectly, which would require both predictor and criterion variables to be measured in such as way as to be highly stable over time and quite consistent across items and observers. Failing that, the process-outcome correlation would be further attenuated by unreliability of measurement.

DeRubeis (2007) presents the results of a simulation analysis of such a study, reporting upper bounds on the size of process-outcome correlations ranging between .2 and .4 , depending on assumptions made. In other words, a correlation of .32 is about as large as one could hope to obtain.

One potential way out of this dilemma is to validate process-outcome associations by experimentally manipulating the therapist process variable, as, for example, Barrett and Berman (2001) did by asking therapists to either increase or decrease the amount of self-disclosure they used. However, this strategy fails to take into consideration the importance of therapist responsiveness (Stiles, Honos-Webb, \& Surko, 1998), which argues that directing therapists to arbitrarily increase or decrease any specific behavior will inevitably make the therapy less responsive and, therefore, less effective. 


\section{Recommendations for Process-Outcome Research}

The other response is to try to use more sophisticated methods to reduce the attenuation between process and outcome sides of the equation by tackling the various measurement and internal validity difficulties. (For more details, see Kazdin, 2009; Kenny \& Hoyt, 2009.) For example, it is theoretically possible to apply causal modeling (e.g., Kline, 2004) to process-outcome research, as follows. First, estimate process and outcome variables using multiple measures, permitting estimation of latent (underlying) variables of putatively perfect reliability and validity. Second, following Stiles et al. (1998), include client resources in the model as a suppressor variable (also measured using multiple indicators); if therapist responsiveness to client resources is operating, then statistically controlling for it should reveal the underlying process-outcome association. This sounds like a reasonable strategy; however, to do this sort of research correctly requires very large samples (i.e., several hundred), beyond the resources that are typically available for such studies. And then there is the problem of defining the client resources variable...

Nevertheless, a recent study by Anderson, Ogles, Patterson, Lambert, and Vermeersch (2009) shows how measuring outcome more robustly and focusing on good process can lead to impressive results. On the predictor side, these researchers used Anderson, Patterson, and Weis's (2007) Facilitative Interpersonal Skills Performance Task, a therapy simulation instrument that rates therapists' recorded responses to brief clips of clients presenting difficult, challenging processes. On the criterion side, they used the client improvement slopes on the Outcome Questionnaire (Lambert et al., 1996), averaged over at least 10 clients. In this study, it appears that several methodological variables combined to produce strong process-outcome results: the use of multiple trained raters rating multiple indicators on a difficult behavioral performance measure of a critical measure good therapy process, plus the use of a robust outcome measure averaged across a large number of clients. I suspect that maximizing the usefulness of the process-outcome design requires conditions comparable to those in this study.

In conclusion, it is my view that the processoutcome design is most valuable for testing welldeveloped, empirically based theories about what works and doesn't work in therapy, especially if those theories focus on key evaluative variables that are carefully measured across an appropriate range of natural variation in a large sample. When those conditions are present, it offers the possibility of providing evidence to support part of a claim for causal mediation, together with evidence that the process preceded the outcome (not always easy to establish) and that other potential background or mediating variables do not better account for outcome (Kazdin, 2009).

\section{The Qualitative Helpful Factors Design}

The emergence of qualitative research over the past 20 years has led to an increasingly popular approach to CPR: asking clients what they found helpful (or unhelpful) in their therapy. Two main alternatives to this helpful factors research have emerged. First, clients can be interviewed, either at the end of therapy or partway through, using a qualitative format such as the Change Interview (Elliott, Slatick, \& Urman, 2001). Each client is interviewed for 30 to $90 \mathrm{~min}$ using a simple interview schedule of four to eight open-ended questions. Clients can simply be asked what they found helpful, useful, or important, or, having described how they have changed over the course of therapy to date, they can be asked what they attribute these changes to. This produces a broad qualitative overview of what the clients perceived as helpful in their therapy, including delayed effects of processes whose impact was diffuse or not immediately apparent. Recent examples of this research genre include Israel, Gorcheva, Burnes, and Walther (2008), Levitt, Butler, and Travis (2006), and Moertl and von Wietersheim (2008). A promising new development within this approach is asking clients about what they also have found helpful in their extratherapy life (Mackrill, 2008).

Second, helpful factors research can also be carried out using a postsession questionnaire, such as the Helpful Aspects of Therapy (HAT) Form (Llewelyn, 1988), asking clients to describe the most helpful or important thing that happened in the session they have just completed and what made this helpful, together perhaps with a simple quantitative rating scale to provide some kind of calibration or means of comparing such significant events from different sessions. This produces accounts of the immediate effects of important change processes as well as a much closer-to-the-ground picture of the helpful factors in therapy, conveying considerably more of the texture of actual therapeutic change.

Helpful factors research produces rich qualitative accounts of change processes that can be used as examples to argue points in systematic single-case study research (Elliott et al., 2009). However, a more common strategy is to use samples of six to 12 interviewees (or more if postsession questionnaire data are used), whose spoken or written accounts are transcribed and analyzed using systematic 
qualitative analysis methods, such as grounded theory (Rennie, Phillips, \& Quartaro, 1988), interpretive phenomenological analysis (Smith, Flowers, \& Larkin, 2009), and consensual qualitative research (Hill et al., 2005). The results typically take the form of multilayered hierarchical systems of categories.

\section{Appeal}

This strategy for identifying change processes has several strengths. First, it is intuitively appealing and consistent with the mental health consumer/service user movement ("Ask the client"). Second, it is relatively easy to carry out helpful factors studies in practice settings and to integrate them within larger research studies such as RCTs in order to shed light on the change process. Third, with the increasing popularity of systematic qualitative research, methods of data collection and analysis are rapidly maturing and promise to produce bodies of research.

\section{Challenges}

Although it is rapidly maturing, the helpful factors design faces several challenges. To begin with, cognitive scientists (e.g., Nisbett \& Ross, 1980) have long argued that people's judgments about causes of events are often wrong. The danger is that clients may make attributional errors, following cultural scripts about the effects and nature of therapy or simply mistakenly attributing to therapy changes that are actually the result of their own efforts independent of therapy, life events, psychobiological processes (e.g., changes in medication or recovery from illness), or even the effects of research (Elliott, 2002). In addition, clients may simply lack the ability to access and verbally express important but subtle change processes, limiting the value of their qualitative accounts. Although not inherent problems with the helpful factors approach, these issues can be exacerbated by poor interviewing and analysis technique (e.g., asking leading questions or relying on superficial descriptions of experience), resulting in misleading or uninteresting results. Finally, trialists and believers in the superiority of quantitative methods (e.g., Lilienfeld, Lynn, \& Lohr, 2003) are likely to dismiss the helpful factors research, branding it as "testimonial," pointing to cases of belief in the efficacy of apparently silly therapies (e.g., thought field therapies), and branding this sort of evidence as both unscientific and inherently untrustworthy.

\section{Recommendations for Helpful Factors Research}

In spite of these limitations, it seems to me that there is clear value in asking clients what they experienced as helpful or change producing. Who else is in a better position to inform us about a client's change process? This is information that we ignore to our detriment. At the same time, it would obviously be a mistake to rely uncritically on client retrospective self-report data as the basis for inferring the causal role of particular aspects of therapy. Thus, helpful factors research should be accepted as one line of evidence for evidence-based practice among others. Furthermore, it is important to encourage better training for qualitative interviewers and the use of deeper, more interpretive or critical analysis of client self-report helpful factors data as a basis for making inferences of its validity. Finally, phenomenological psychologists concede the existence of informant distortions in qualitative accounts but address the issue by, for example, focusing on matters of importance to informants (Wertz, 1986) and careful listening for modes of informant self-deception as a way of distinguishing "between truth and groundless assertion" (Churchill, 2000, p. 59).

Along these lines is the intriguing possibility of combining qualitative helpful factors research with interpretive single-case methods, which are at the forefront in the evaluation of the validity of client self-report. For example, hermeneutic single-case efficacy design (Elliott, 2002; Elliott et al., 2009) makes the credibility of clients as witnesses to their own change process a central consideration by systematically looking for evidence of client relationally based or self-deceptive attributional biases in favor of therapeutic effectiveness. Helpful factors methods are key to this brand of case study research but are examined critically and must be bolstered by evidence for their credibility.

As qualitative helpful factors studies accumulate, it has become important to develop methods for integrating qualitative studies to provide broad views of how change occurs, that is, qualitative metaanalysis or meta-synthesis (e.g., Finfgeld, 2003). Together with colleagues, I carried out an early systematic qualitative meta-analysis (Greenberg, Elliott, \& Lietaer, 1994), reviewing 14 studies of helpful factors in person-centered experiential therapies. From each study, we selected the five most strongly rated or frequently described helpful aspects. We found 14 types of helpful aspects, organized into four larger groups: positive relational environment (e.g., empathy, support; seven of 14 data sets), client's therapeutic work (e.g., self-disclosure, exploration; 13 sets), therapist facilitation of client's work (e.g., fostering exploration, giving feedback; six sets), and client changes or impacts (e.g., awareness, positive feelings; 12 sets). A more recent example is Timulak's (2007) qualitative meta-analysis of the results of seven studies of the immediate effects of

445 
significant therapy events in a mixture of therapies. $\mathrm{He}$ obtained nine categories that replicated across studies, the most prevalent being awareness/insight/ self-awareness and reassurance/support/safety (both occurred in all seven studies), with three other categories occurring in more than half of the studies: behavior change/problem solution; exploring feelings/emotional experiencing; and feeling understood.

In the end, as I see it, qualitative research is most useful not for testing theories of how change occurs in therapy but for developing those theories in the first place, for developing and modifying rich theory grounded in data. For example, helpful factors research was the source of Stiles's assimilation model (e.g., Stiles et al., 1990). In addition, such studies have a potentially valuable role in identifying problems and improving the application of a particular type of therapy with a particular client population. They are also a powerful strategy for providing mental health service users with a scientifically sanctioned voice for expressing their views about what works or does not work in psychotherapy. As such, helpful factors studies are an important approach to CPR, among others.

\section{The Microanalytic Sequential Process Design}

Far less common is research on the turn-to-turn insession interaction between client and therapist. Microanalytic sequential process research is typically low-level quantitative in nature, coding client and therapist responses on a relatively small number of categories or rating scales. Such studies examine the direct, immediate influence of therapeutic interventions on within-session client processes and also the effect of client actions on the processing and planning activities of the therapist. Sequential process research involves questions such as "What client processes are triggered by what therapist responses under what conditions?" Thus, sequential process studies primarily involve establishing relationships among process variables themselves (e.g., between responses by the therapist and those of the client). Most commonly, such research has looked at the effects of particular kinds of therapist intervention (e.g., therapist interpretation, exploratory questions) in relationship to a measure of productive or unproductive client process (e.g., client experiencing or insight). Studies by Sachse (1992) and Wiseman and Rice (1989) are examples of this form of sequential process research. Alternatively, dimensional therapist variables, such as depth of interpretation (Speisman, 1959), have been examined in relation to levels of productive client process. Finally, a small number of early, pioneering reports studied sequences of client and therapist in-session actions in order to construct models of common therapeutic sequences (e.g., Frank \& Sweetland, 1962; Snyder, 1945).

As noted, sequential process studies typically focus on a small number of process variables, which means that they lend themselves to testing theories about fundamental processes of influence in therapy sessions. Such theories include, for example, the psychodynamic proposition that transference interpretations lead to client insight or the person-centered experiential expectation that therapist empathy facilitates deeper client experiencing.

An important and controversial recent example of sequential process research is Sachse's (1992); see summary in Sachse \& Elliott, 2002) series of studies on the relationship between therapist processing proposals and client level of self-exploration. To demonstrate the process-directive nature of the therapist's influence on the client person-centered therapy, samples of three successive client-therapistclient (CTC) speaking turns were rated using parallel 8-point scales. Then Sachse looked at the influence of therapist responses that were at the same level as, or lower or higher than, the previous client response. He found that clients were strongly influenced by the level of processing proposed by their therapists, which he claimed violated the nondirectivity precept of classic person-centered therapy.

\section{Appeal}

Because it closely follows the concrete actions of client and therapist, microanalytic sequential process research has great potential for testing key theoretical claims about fundamental therapeutic influence processes. Furthermore, the sequential nature of the CTC data means that three of Haynes and O'Brien's (2000) key conditions for causal inference are readily achieved: (a) covariation between therapist and client responses; (b) therapist response preceding the following client response (TC); and (c) a plausible explanation for the causal relationship in the form of the theory being tested. Moreover, the sequential process design can go further by pointing directly to the causal process as it happens. That is, the therapist response can be seen to "touch" the following client response in two ways. First, there is little or no separation between the two successive responses (the therapist speaks and then the client speaks next). Second, widely recognized causal processes in the form of conversational constraints can be shown to operate between successive speaking turns (Schegloff, 2007). Thus, sequential process research offers the possibility of detecting and demonstrating strong causal influence. Finally, because they are so closely grounded in therapy 
process, the results of sequential process studies are also potentially useful for guiding practice.

\section{Challenges}

Given the potential power of the sequential process design in CPR and its firm grounding in concrete clinical practice, one might ask why it is not more widely used. A first limitation is the potentially wide gap between very specific within-session causal processes and therapy outcome. Demonstrating that the therapist helps clients deepen their process within sessions does not tell us whether or how this translates into posttherapy outcome. Obviously, this limits the practical value of sequential process studies. Second, reverse (client-to-therapist) causation is not the only alternative explanation that needs to be ruled out: Third-variable causation may also operate, in the form of broader variables such as the momentary state of the therapeutic alliance, which may be affecting both client and therapist responses. Third, and relatedly, sequential process studies typically ignore influence processes that extend beyond the immediately preceding response (referred to as the "lag 1" sequence in times-series analysis; Greenberg, 1986); extending the examined sequences further back in time greatly complicates matters.

The major limitation of sequential process research is, unfortunately, that it is difficult and time consuming. To do this kind of research, one first has to select and transcribe relevant segments of therapy process, then train raters to acceptable levels of reliability, and finally analyze the data using special statistics. (The usual statistics are not appropriate because the data typically violate the critical statistical assumption of independence of observations.) The cumbersome nature of the research also means that it is not particularly good for discovery-oriented research; it is more difficult to investigate the full range of possible third-variable causes, including previous speaking turns, therapeutic alliance, client resources, and so on. Probably for these reasons, the sequential process design has never really caught on. If anything, over the past 20 years it has been pushed further out of prominence by the current emphasis on outcome research and RCTs.

\section{Recommendations for Microanalytic Sequential Process Research}

Sequential process research is, nevertheless, an intuitively appealing, practice-near approach that is capable of providing the basis for strong causal inference about important therapeutic change processes. For this reason, it needs to be accepted as a key line of evidence supporting evidence-based practice. In addition, combining sequential process research with process-outcome research can strengthen it; that is, once a therapist-to-client withinsession sequence has been identified, it can be used to predict posttherapy outcome, thus partially filling in the process-to-outcome gap. Another recent, potentially helpful development is the emergence of statistical methods appropriate for sequentially dependent observations, including time-series panel analysis, multilevel modeling, and growth-curve modeling (Tschacher \& Ramseyer, 2009).

Curiously, sequential process research has to date been primarily quantitative in nature. Qualitative microanalytic research is underdeveloped and in my view should be used more widely. For example, therapy researchers (e.g., Russell \& Czogalik, 1989; Siegfried, 1995) have discussed the potential value of conversation analysis (CA; e.g., Schegloff, 2007), the best developed qualitative sequential process method, for several decades. Unfortunately, most CA research on psychotherapy has so far looked more generally and descriptively at the conversation structure of therapy sessions rather specifically focusing on the change process. The result is that the full potential of this powerful and rigorous form of qualitative sequential process research has not yet been adequately developed; it remains a promising but not yet fully explored possibility. Two recent books provide potentially useful directions for the application of CA to change in psychotherapy (Pain, 2009; Peräkylä, Antaki, Vehviläinen, \& Leudar, 2008).

Finally, it is worth pointing out that qualitative microanalytic sequential process methods, including $\mathrm{CA}$, have been incorporated into more complex forms of CPR focusing on significant change events, discussed next.

\section{The Significant Events Approach}

The three basic forms of CPR described all represent approaches that offer different lines of evidence that can be brought to bear on a hypothetically important therapeutic process. All have complementary strengths as well as important limitations, many of which have been noted along the way. For this reason, researchers have created complex mixed genres that combined the basic CPR designs and qualitative and quantitative data collection, generally within an interpretive, theory-building framework. The two oldest of these are task analysis (e.g., Rice \& Greenberg, 1984; Greenberg, 2007; Pascual-Leone, Greenberg, \& Pascual-Leone, 2009) and comprehensive process analysis (e.g., Elliott et al., 1994), but assimilation analysis (Stiles et al., 1990) is a more recent example that grew out of the latter. 
What these complex approaches generally have in common is a focus on important moments in therapy. The moments studied were originally focused on helpful events, such as insight (e.g., Elliott, 1984; Elliott et al., 1994), empowerment (Timulak \& Elliott, 2003), resolution of therapeutic tasks (e.g., conflict splits; Greenberg, 1984), and the various transition points mapped by Stiles's (1999, 2006) assimilation model (e.g., Brinegar, Salvi, Stiles, \& Greenberg, 2006). Over time, however, researchers have come to focus more attention on hindering or disruptive events such as difficult moments (e.g., Davis et al., 1987), relational ruptures (Safran, Crocker, McMain, \& Murray, 1990), and misunderstandings (Rhodes, Hill, Thompson, \& Elliott, 1994).

Task analysis, adapted from cognitive science by Rice and Greenberg (1984; see Greenberg, 2007), typically identifies an important therapeutic task (e.g., helping clients resolve puzzlement over something they did or felt) and then examines successful and unsuccessful client performances in order to build and test models of how to help clients resolve these tasks. Process-experiential/emotion-focused therapy (Greenberg, Rice, \& Elliott, 1993) was developed through task analysis research. Alternatively, comprehensive process analysis (e.g., Elliott, 1989; Elliott et al., 1994) works more inductively from important moments of therapeutic change in order to explain and model their components and unfolding effects as well as the contexts from which they arose.

Significant events studies generally share several methodological features. First, they use some sort of strategy for identifying important moments of therapy. In other words, significant events research incorporates helpful factors methods as a key part of their method. These methods range from simple client self-reports such as the HAT Form (developed by Llewelyn, 1988, to identify significant therapy events), to observational methods for reviewing therapy sessions (e.g., Greenberg, 2007), to videoassisted client interview methods (e.g., Brief Structured Recall; Elliott \& Shapiro, 1988). Often, a combination of two or more of these methods is used (e.g., observers use the client's description on a HAT Form to locate the event referred to in the session).

Second, once one or more events have been identified, the researchers try to develop a qualitative, sequential description of what happened, tracking multiple aspects of client and therapist process as they unfold step by step over time within, and in some cases across, sessions. That is, significant events studies also make use of sequential process methods; the main difference is that significant events research typically tracks multiple parallel qualitative aspects, whereas traditional sequential process studies focus on one or two quantitative parameters. In other words, the traditional sequential process design is good for testing theories, whereas qualitative sequential analysis within the significant event approach is aimed at building and adapting theories (e.g., Elliott, Slatick, \& Urman, 2000). Furthermore, the rich sequential information used in significant events studies, because of its complexity, lends itself to theory-building case study methods in precisely the ways defined by Stiles (2007).

Third, significant events studies generally try to tie within-session processes to postsession outcomes and, typically, to posttherapy outcomes as well. This means that this approach also incorporates the process-outcome strategy of looking for connections between in-session process and outcome. This is sometimes done in a comparative way, as in the Rhodes et al. (1994) study, which looked at resolved versus unresolved misunderstandings, or in validation phase task analysis studies (Greenberg, 2007), in which high and low task resolvers (e.g., in a twochair approach for conflict splits) are contrasted to determine which elements are needed for resolution. However, significant event studies often tie process to outcome in a more descriptive, noncomparative way, by trying to model either good or poor resolution or outcome events but not both. Although this goes against the common knowledge development strategy of comparing things, the argument for a noncomparative approach is that careful, descriptive theory building trumps comparative theory testing, at least in the initial rational model construction phase of research. The theory built in discovery phase descriptive case study research can be tested in validation comparative theory-testing studies (Greenberg, 2007).

\section{Appeal}

Significant events studies generally operate at a level of concreteness and explicitness (including frequent use of clinical examples and transcripts) close to practice, which gives greater natural appeal for therapists. They are particularly useful for explicating therapist implicit knowledge and translating findings into clinical microtheories (Rice \& Greenberg, 1984). They are highly flexible and can be used to study a wide variety of therapies and types of events. By integrating the other, more basic forms of CPR, they build on their strengths and minimize the impact of their weaknesses, providing a set of converging operations to evaluate the causal role of particular change processes. Finally, they typically go far beyond simple one- or two-factor models of the 
change process, encouraging richer, more clinically relevant and representative integrative models.

\section{Challenges}

However, like microanalytic sequential process studies, these complex forms of significant events research have not yet been widely used, probably for many of the same reasons. Primarily, these methods are technically demanding to learn and time consuming to carry out. Their intense focus on small numbers of key moments in therapy has often led to studies of single significant events, which have sometimes been difficult to publish and are also slow to build up into bodies of knowledge (but see Iwakabe \& Gazzola, 2009, for a review of emerging strategies for synthesizing such case study research). Their complexity means that they are not suited to one-shot investigations but instead define programs of research (which may not be a disadvantage, in fact). Finally, it can be argued that significant events research is based on a specific model of therapy as task focused and centered on the client as active change agent, which may not suit some approaches to therapy.

\section{Recommendations for Significant Events Research}

Significant events studies have, nevertheless, made important contributions to the development of therapies such as process-experiential/emotion-focused therapy (Elliott, Watson, Goldman, \& Greenberg, 2004) and Safran and Muran's (2000) interpersonal approach in particular, suggesting that further application of these demanding approaches would be likely to lead to further useful developments. I offer some suggestions for the use of the significant events approach to CPR. First, task analysis can start by interviewing expert therapists about their practice in particular clinical situations or with particular client markers or presentations. This approach has been underutilized but should appeal to qualitative researchers as an initial step in a significant events approach. Second, assimilation analysis and comprehensive process analysis in particular lend themselves for use in single-case or small-sample student research projects in professional training programs, staying close to clinical practice, significant events studies can appeal to practice-oriented students in many of the same ways that qualitative interview studies do, while actually being more grounded in practice by virtue of exposing students to actual therapeutic practice as opposed to talk about practice. Third, it may be useful to extend the idea of as alternatives to qualitative interview research. By significant events research to understanding whole therapies. One way of doing this is to track how a particular issue changes over therapy, as in the assimilation model (e.g., Stiles et al., 1990). Another way is to look at the whole therapy causally, building a model of the interaction between therapeutic and other change processes (e.g., psychobiological factors, life events, internally generated client selfchange, effects of research), as is done in hermeneutic single-case efficacy design (Elliott et al., 2009).

\section{Conclusion: Systematic Methodological Pluralism}

I have argued that CPR methods have not fully realized their potential to contribute to our understanding of how clients change. Of the basic designs, the process-outcome approach has been used quite extensively in spite of documented difficulties and could do with being balanced by greater use of the others. Some, such as the sequential process design, have never fully caught on in spite of their promise and remain underutilized. However, each of the three basic designs faces challenges as fallible, partial approaches to understanding how change occurs in therapy. A fourth, more complex approach to CPR, which I have referred to as the significant events design, has attempted to overcome these limitations by integrating the first three. Unfortunately, pulling these different methods into a single complex approach also makes significant events research time consuming and technically difficult.

The goal of this critical assessment, however, is not to depress the reader but rather to point out that these four types of CPR have proven useful over the past 60 years of therapy research and can be improved upon further through careful application and balanced, pluralistic research practice. Actually, the existence of this set of different approaches provides an important methodological resource for psychotherapy researchers. This is because it allows for multiple complementary strategies for identifying key causal change processes in therapy as well as multiple lines of evidence for testing these change processes.

It is thus my view that future progress on how clients change in therapy is likely to benefit most strongly from a more balanced approach that brings all available methodological tools to bear on the problem. This can be done either by integrating the different basic designs within a given study, as in significant events research, or by encouraging the full range of designs across studies and research programs. Overall, what I believe is most needed is systematic methodological pluralism, requiring all four lines of evidence to provide a more sound
875

880 
foundation for the evidence-based practice of psychotherapy.

Table $I$ is an attempt to provide a basis for this systematic methodological pluralism by summing up the different strengths and weakness of these four designs. I have grouped these features under two headings. First, causal inference criteria refers to the initial focus of this article on the potential of these designs for grounding useful inferences about the causal role of particular therapeutic processes in bringing about client change. The first four of these were introduced at the beginning; the next two ("demonstrate construct validity of cause/effect" and "direct relevance to clinical practice") are derived from Cook and Campbell's (1979) elegant formulation of the basis of generalizable causal inference; and the last ("provide direct causal evidence") is a feature of qualitative research in which clients can be called upon as expert witnesses on the causes of their own change process, in effect bypassing the other causal conditions. Second, practical criteria involve other aspects of the different designs that are likely to affect their uptake, including installed user base ("popularity of use") and appeal to researchers ("ease of use"), clients or service users ("client/service user-friendly"), and therapists ("relevance to clinical complexity").

The point is this exercise is not to grade the different approaches; I have tried to make it clear that each of these designs, by itself, has both strengths and weaknesses. Different reviewers of these approaches will undoubtedly evaluate them differently: Qualitative researchers can be expected to favor helpful factors and significant events designs, while quantitative researchers would be most likely to prefer process-outcome and sequential process designs. Personally, I do see the helpful factors design as having much to offer in terms of directness, clinical relevance, ease of use, popularity, plausibility, and service user involvement; I also believe that the significant events and sequential process designs, although underutilized, have multiple merits that warrant wider use. At the same time, I must confess a continuing fondness for the process-outcome design in spite of the controversy over its use, particularly if practical self-report measures of process (e.g., client ratings of alliance) are used and temporal precedence is carefully considered.

It is also useful to review Table I in order to consider which design criteria are most readily satisfied by a variety of designs and which are more difficult to meet. For example, documenting temporal precedence, relevance to clinical practice, and providing direct causal evidence can all be met by most of the different designs. For other criteria, there is often only one design that does a good job: the helpful factors design for ease of use and client/ service user friendly; the significant events design for relevance to clinical complexity). Finally, two of the casual inference criteria are difficult to meet with any of the designs: consider alternate causes and demonstrate construct validity of cause/effect. In other words, none of the four designs has been consistently used to rigorously look for nontherapy causes (e.g., other relationships, biological factors) or to address measurement issues (e.g., by using multiple measures for the same thing). The significant events approach does allow for this level of complexity but often ignores internal and construct validity issues (but see Pascual-Leone et al., 2009). In my view, these problems are not insurmountable, but they do require further attention.

My advocacy of systematic methodological pluralism is in direct contrast to the one-sided emphasis in the field of psychotherapy research today on one particular form: RCTs. As noted earlier, it is possible to design RCTs that systematically vary one or two process variables across conditions. Such treatment component designs most commonly include therapy knockout (by analogy to gene knockout studies; Kazdin, 2009) or dismantling studies, in which one
970

975

Table I. Change Process Research Designs: Causal Inference and Practical Criteria

\begin{tabular}{|c|c|c|c|c|}
\hline Feature & Process-outcome & Helpful factors & Sequential process & Significant events \\
\hline \multicolumn{5}{|l|}{ Causal inference criteria } \\
\hline Document temporal precedence & Sometimes & Yes & Yes & Yes \\
\hline Provide plausible explanation & No & Yes & Qualitative versions & Yes \\
\hline Show covariation & Yes & No & Yes & Sometimes \\
\hline Consider alternate causes & Sometimes & No & No & Sometimes \\
\hline Demonstrate construct validity of cause/effect & Sometimes & No & No & Sometimes \\
\hline Direct relevance to clinical practice (generalizability) & No & Yes & Yes & Yes \\
\hline Provide direct causal evidence & No & Yes & Yes & Yes \\
\hline \multicolumn{5}{|l|}{ Practical criteria } \\
\hline Popularity of use & Yes & Yes & No & No \\
\hline Ease of use & Self-report versions & Yes & No & No \\
\hline Client/service user-friendly & No & Yes & No & Sometimes \\
\hline Relevance to clinical complexity & No & No & No & Yes \\
\hline
\end{tabular}


element of therapy is removed (e.g., taking the cognitive element out of the cognitive-behavioral therapy; Jacobson et al., 1996), or additive studies, where a new therapeutic element is introduced (e.g., adding active therapeutic tasks to person-centered therapy; Greenberg \& Watson, 1998).

Treatment component RCTs, however, are relatively scarce in the empirical literature. Most commonly, one kind of therapy, such as cognitivebehavioral, is contrasted with another kind, such as short-term psychodynamic therapy. Unfortunately, such a design is not a valid basis for making causal inferences about particular therapeutic change processes. There are simply too many differences between two complex treatment packages. Such studies lack conceptual clarity and are, therefore, not examples of CPR.

Instead, any one of the designs reviewed here provides a sounder basis for inferring the operation of particular therapy processes in bringing about client change. The optimal strategy, however, is to use several different CPR designs, within or across studies, to build a convincing case for a particular change process. Take, for example, relational depth (Mearns \& Cooper, 2005), a newly minted formulation for a powerful state of felt connectedness between client and therapist. To make a strong case for the causal efficacy of this change process, researchers might want to start with helpful factors studies in order to document the existence and general nature of moments of relational depth (e.g., Knox, 2008). Next, significant events studies using comprehensive process analysis or task analysis could be used to develop and refine models of how client and therapist behaviors and experiences unfold and interact during episodes of relational depth. These models could be further tested at a microprocess level using the sequential analysis approach. Finally, quantitative measures (e.g., Wiggins, 2009) could be developed and used in process-outcome studies to predict therapy outcome. A body of such complementary studies would go a long way toward establishing the causal efficacy of relational depth in bringing about change in therapy, something that would be difficult, if not impossible, using RCTs.

By describing these CPR designs, including their appeal, limitations, and recommendations for when and how best to use them, I hope to have provided a useful guide that psychotherapy researchers can use to expand their options, increase the quality of their causal inferences, and enhance the clinical relevance, service-user relevance, and usefulness of their research. It seems to me that psychotherapy researchers are sometimes shy about aspiring to causal inference; my point here has been that the tools of CPR are essential for identifying, describing, and testing important processes that bring about therapeutic change. Ultimately, when taken as a group, these methods provide a sound basis for establishing the causal role of particular therapeutic processes in helping clients bring about change in themselves.

\section{Acknowledgement}

An earlier version of this article was presented at the meeting of the Society for Psychotherapy Research, Madison, WI, June 2007.

\section{References}

Anderson, T., Ogles, B. M., Patterson, C. L., Lambert, M. J., \& Vermeersch, D. V. (2009). Therapist effects: Facilitative interpersonal skills as a predictor of therapist success. Fournal of Clinical Psychology, 65, 755-768.

Anderson, T. Patterson, C. L., \& Weis, A. C. (2007). Facilitative interpersonal skills performance analysis rating method. Unpublished coding manual, Department of Psychology, Ohio University, Athens, $\mathrm{OH}$.

Barrett, M. S., \& Berman, J. S. (2001). Is psychotherapy more effective when therapists disclose information about themselves? Fournal of Consulting and Clinical Psychology, 69, 597-603.

Bohart, A. C., Elliott, R., Greenberg, L. S., \& Watson, J. C. (2002). Empathy. In J. Norcross (Ed.), Psychotherapy relationships that work (pp. 89-108). New York: Oxford University Press.

Brinegar, M. G., Salvi, L. M., Stiles, W. B., \& Greenberg, L. S. (2006). Building a meaning bridge: Therapeutic progress from problem formulation to understanding. Fournal of Counseling Psychology, 53, 165-180.

Christman, S. D., Garvey, K. J., Propper, R. E., \& Phaneuf, K. A. (2003). Bilateral eye movements enhance the retrieval of episodic memories. Neuropsychology, 17, 221-229.

Churchill, S. (2000). "Seeing through" self-deception in narrative reports: Finding psychological truth in problematic data. fournal of Phenomenological Psychology, 31, 44-62.

Cook, T. D., \& Campbell, D. T. (1979). Quasi-experimentation: Design and analysis issues for field settings. Chicago: Rand McNally.

Crits-Christoph, P., \& Connolly Gibbons, M. B. (2002). Relational interpretations. In J. Norcross (Ed.), Psychotherapy relationships that work (pp. 285-300). New York: Oxford University Press.

Davis, J. D., Elliott, R., Davis, M. L., Binns, M., Francis, V. M., Kelman, J., et al. (1987). Development of a taxonomy of therapist difficulties: Initial report. British fournal of Medical Psychology, 60, 109-119.

DeRubeis, R. J. (2007, June). I can sense us coming to a consensus, and other wishes. Paper presented at the meeting of the Society for Psychotherapy Research, Madison, WI.

DeRubeis, R. J., Brotman, M. A., \& Gibbons, C. J. (2005). A conceptual and methodological analysis of the nonspecifics argument. Clinical Psychology: Science and Practice, 12, 174-183.

Elliott, R. (1984). A discovery-oriented approach to significant events in psychotherapy: Interpersonal process recall and comprehensive process analysis. In L. Rice \& L. Greenberg (Eds.), Patterns of change (pp. 249-286). New York: Guilford Press.

Elliott, R. (1989). Comprehensive process analysis: Understanding the change process in significant therapy events. In M. 
Packer \& R. B. Addison (Eds.), Entering the circle: Hermeneutic investigation in psychology (pp. 165-184). Albany, NY: SUNY Press.

Elliott, R. (2002). Hermeneutic single case efficacy design. Psychotherapy Research, 12, 1-20.

Elliott, R., Partyka, R., Alperin, R., Dobrenski, R., Wagner, J., Messer, S. B., et al. (2009). An adjudicated hermeneutic singlecase efficacy design of experiential therapy for panic/phobia. Psychotherapy Research, 19, 543-557.

Elliott, R., \& Shapiro, D. A. (1988). Brief structured recall: A more efficient method for identifying and describing significant therapy events. British fournal of Medical Psychology, 61, 141-153.

Elliott, R., Shapiro, D. A., Firth-Cozens, J., Stiles, W. B., Hardy, G., Llewelyn, S. P., et al. (1994). Comprehensive process analysis of insight events in cognitive-behavioral and psychodynamic-interpersonal therapies. Fournal of Counseling Psychology, 41, 449-463.

Elliott, R., Slatick, E., \& Urman, M. (2000). "So the fear is like a thing ...": A significant empathic exploration event in processexperiential therapy for PTSD. In J. Marques-Teixeira \& S. Antunes (Eds.), Client-centered and experiential psychotherapy (pp. 179-204). Linda a Velha, Portugal: Vale \& Vale.

Elliott, R., Slatick, E., \& Urman, M. (2001). Qualitative change process research on psychotherapy: Alternative strategies. In J. Frommer \& D. L. Rennie (Eds.), Qualitative psychotherapy research: Methods and methodology (pp. 69-111). Lengerich, Germany: Pabst Science.

Elliott, R., Watson, J. C., Goldman, R. N., \& Greenberg, L. S. (2004). Learning emotion-focused therapy: The process-experiential approach to change. Washington, DC: American Psychological Association.

Finfgeld, D. L. (2003). Metasynthesis: The state of the art - so far. Qualitative Health Research, 13, 893-904.

Frank, G. H., \& Sweetland, A. A. (1962). A study of the process of psychotherapy: The verbal interaction. Fournal of Consulting Psychology, 26, 135-138.

Greenberg, L. S. (1984). A task analysis of intrapersonal conflict resolution. In L. Rice \& L. Greenberg (Eds.), Patterns of change (pp. 67-123). New York: Guilford Press.

Greenberg, L. S. (1986). Change process research. Fournal of Consulting and Clinical Psychology, 54, 4-9.

Greenberg, L. S. (2007). A guide to conducting a task analysis of psychotherapeutic change. Psychotherapy Research, 17, 15-30.

Greenberg, L. S., Elliott, R., \& Lietaer, G. (1994). Research on humanistic and experiential psychotherapies. In A. E. Bergin \& S. L. Garfield (Eds.), Handbook of psychotherapy and behavior change (4th ed., pp. 509-539). New York: Wiley.

Greenberg, L. S., Rice, L. N., \& Elliott, R. (1993). Facilitating emotional change. New York: Guilford Press.

Greenberg, L. S., \& Watson, J. (1998). Experiential therapy of depression: Differential effects of client-centered relationship conditions and active experiential interventions. Psychotherapy Research, 8, 210-224.

Haynes, S. N., \& O'Brien, W. O. (2000). Principles of behavioral assessment: A functional approach to psychological assessment. New York: Plenum.

Herbert, J. D., Lilienfield, S. O., Lohr, J. M., Montgomery, R. W., O'Donohue, W. T., Rosen, G. M., et al. (2000). Science and pseudoscience in the development of EMDR. Clinical Psychology Review, 20, 945-971.

Hill, C. E., Knox, S., Thompson, B. J., Williams, E. N., Hess S. A., \& Ladany, N. (2005). Consensual qualitative research: An update. Fournal of Counseling Psychology, 52, 196-205.
Israel, T., Gorcheva, R., Burnes, T., \& Walther, W. (2008). Helpful and unhelpful experiences of LGBT therapy clients. Psychotherapy Research, 18, 294-305.

Iwakabe, S., \& Gazzola, N. (2009). From single-case studies to practice-based knowledge: Aggregating and synthesizing case studies. Psychotherapy Research, 19, 601-611.

Jacobson, N. S., Dobson, K. S., Truax, P. A., Addis, M. E., Koerner, K., Golan, J. K., et al. (1996). A component analysis of cognitive-behavioral treatment for depression. Fournal of Consulting and Clinical Psychology, 64, 295-304.

Kazdin, A. E. (2009). Understanding how and why psychotherapy leads to change. Psychotherapy Research, 19, 419-428.

Kenny, D. A., \& Hoyt, W. T. (2009). Multiple levels of analysis in psychotherapy research. Psychotherapy Research, 19, 462-468.

Kline, R. B. (2004). Principles and practice of structural equation modeling (2nd ed). New York: Guilford Press.

Knox, R. (2008). Clients' experiences of relational depth in person-centred counselling. Counselling and Psychotherapy Research, 8(3), 182-188.

Lambert, M. J., Burlingame, G. M., Umphress, V., Hansen, N., Yanchar, S. C., Vermeersch, D., et al. (1996). The reliability and validity of a new psychotherapy outcome questionnaire. Clinical Psychology and Psychotherapy, 3, 249-258.

Levitt, H. M., Butler, M., \& Travis, H. (2006). What clients find helpful in psychotherapy: Principles for facilitating change. fournal of Counseling Psychology, 53, 314-324.

Lilienfeld, S. O. Lynn, S. J. \& Lohr, J. M. (Eds.). (2003). Science and pseudoscience in clinical psychology. New York: Guilford Press.

Llewelyn, S. (1988). Psychological therapy as viewed by clients and therapists. British fournal of Clinical Psychology, 27, 223-238.

Mackrill, T. (2008). Exploring psychotherapy clients' independent strategies for change while in therapy. British fournal of Guidance and Counselling, 36, 441-453.

Martin, D. J., Garske, J. P., \& Davis, M. K. (2000). Relation of therapeutic alliance with outcome and other variables: A metaanalytic review. Fournal of Consulting and Clinical Psychology, 68, 438-450.

Mearns, D., \& Cooper, M. (2005). Working at relational depth in counselling and psychotherapy. London: Sage.

Moertl, K., \& von Wietersheim, J. (2008). Client experiences of helpful factors in a day treatment program: A qualitative approach. Psychotherapy Research, 18, 281-293.

Nisbett, R., \& Ross, L. (1980). Human inference: Strategies and shortcomings of human judgement. Englewood Cliffs, NJ: Prentice Hall.

Orlinsky, D. E., Rønnestad, M. H., \& Willutzki, U. (2004). Process and outcome in psychotherapy. In M. J. Lambert (Ed.), Bergin and Garfield's handbook of psychotherapy and behavior change (5th ed., pp. 307-389). New York: Wiley.

Pain, J. (2009). Not just talking: Conversational analysis, Harvey Sacks' gift to therapy. London: Karnac Books.

Pascual-Leone, A., Greenberg, L. S., \& Pascual-Leone, J. (2009). Developments in task analysis: New methods to study change. Psychotherapy Research, 19, 527-542.

Peräkylä, A., Antaki, C., Vehviläinen, S., \& Leudar, I. (Eds.). (2008). Conversation analysis and psychotherapy: Psychotherapy in practice. Cambridge, UK: Cambridge University Press.

Rennie, D. L., Phillips, J. R., \& Quartaro, G. K. (1988). Grounded theory: A promising approach to conceptualization in psychology? Canadian Psychology, 29, 139-150.

Rhodes, R. H., Hill, C. E., Thompson, B. J., \& Elliott, R. (1994). Client retrospective recall of resolved and unresolved misunderstanding events. Fournal of Counseling Psychology, 41, 473-483. 
Rice, L. N. \& Greenberg, L. (Eds.). (1984). Patterns of change. New York: Guilford Press.

Rogers, C. R. (1957). The necessary and sufficient conditions of therapeutic personality change. Fournal of Consulting Psychology, 21, 95-103.

Russell, R. L., \& Czogalik, D. (1989). Strategies for analyzing conversations: Frequencies, sequences, or rules. Fournal of Social Behavior and Personality, 4, 221-236.

Sachse, R. (1992). Differential effects of processing proposals and content references on the explication process of clients with different starting conditions. Psychotherapy Research, 2, 235-251.

Sachse, R., \& Elliott, R. (2002). Process-outcome research in client-centered and experiential therapies. In D. Cain \& J. Seeman (Eds.), Humanistic psychotherapies: Handbook of research and practice (pp. 83-115). Washington, DC: American Psychological Association.

Safran, J. D., Crocker, P., McMain, S., \& Murray, P. (1990). Therapeutic alliance rupture as a therapy event for empirical investigation. Psychotherapy, 27, 154-165.

Safran, J. D., \& Muran, J. C. (2000). Negotiating the therapeutic alliance: $A$ relational treatment guide. New York: Guilford Press.

Schegloff, E. A. (2007). Sequence organization in interaction: $A$ primer in conversation analysis (Volume 1). Cambridge, UK: Cambridge University Press.

Shapiro, F. (1995). Eye movement desensitization and reprocessing. Basic principles, protocols, and procedures. New York: Guilford Press.

Siegfried, J. (Ed.). (1995). Therapeutic and everyday discourse as behavior change: Towards a micro-analysis in psychotherapy process research. Norwood, NJ: Ablex.

Smith, J. A., Flowers, P., \& Larkin, M. (2009). Interpretative phenomenological analysis: Theory, method and research. London: Sage.

Snyder, W. U. (1945). An investigation of the nature of nondirective psychotherapy. Fournal of General Psychology, 33, 193-223.

Speisman, J. C. (1959). Depth of interpretation and verbal resistance in psychotherapy. Fournal of Consulting Psychology, 23, 93-99.

Stiles, W. B. (1988). Psychotherapy process-outcome correlations may be misleading. Psychotherapy, 25, 27-35.
Stiles, W. B. (1996). When more of a good thing is better: Reply to Hayes et al. (1996). Fournal of Consulting and Clinical Psychology, 64, 915-918.

Stiles, W. B. (1999). Signs and voices in psychotherapy. Psychotherapy Research, 9, 1-21.

Stiles, W. B. (2006). Assimilation and the process of outcome: Introduction to a special section. Psychotherapy Research, 16, 389-392.

Stiles, W. B. (2007). Theory-building case studies of counselling and psychotherapy. Counselling and Psychotherapy Research, 7, 122-127.

Stiles, W. B., Elliott, R., Llewelyn, S. P., Firth-Cozens, J. A., Margison, F. R., Shapiro, D. A., et al. (1990). Assimilation of problematic experiences by clients in psychotherapy. Psychotherapy, 27, 411-420.

Stiles, W. B., Honos-Webb, L., \& Surko, M. (1998). Responsiveness in psychotherapy. Clinical Psychology: Science and Practice, $5,439-458$

Stiles, W. B., \& Shapiro, D. A. (1989). Abuse of the drug metaphor in psychotherapy process-outcome research. Clinical Psychology Review, 9, 521-543.

Stiles, W. B., \& Shapiro, D. A. (1994). Disabuse of the drug metaphor: Psychotherapy process-outcome correlations. Fournal of Consulting and Clinical Psychology, 62, 942-948.

Timulak, L. (2007). Identifying core categories of client-identified impact of helpful events in psychotherapy: A qualitative metaanalysis. Psychotherapy Research, 17, 305-314.

Timulak, L., \& Elliott, R. (2003). Empowerment events in process-experiential psychotherapy of depression: A qualitative analysis. Psychotherapy Research, 13, 443-460.

Tschacher, W., \& Ramseyer, F. (2009). Modeling psychotherapy process by time-series panel analysis (TSPA). Psychotherapy Research, 19, 469-481.

Wertz, F. J. (1986). The question of reliability in psychological research. Fournal of Phenomenological Psychology, 17, 181-205.

Wiggins, S. (2009, March). Developing the Relational Depth Inventory: Prevalence, moderators $\mathbb{E}$ characteristics of relational depth events. Paper presented at the meeting of the UK Chapter of the Society for Psychotherapy Research, Ravenscar, UK.

Wiseman, H., \& Rice, L. N. (1989). Sequential analyses of therapist-client interaction during change events: A taskfocused approach. Fournal of Consulting and Clinical Psychology, $57,281-286$. 